\title{
Plasma cell proliferation in monoclonal gammopathies: measurement using BU-1 antibody in flow cytometry and microscopy: comparison with serum thymidine kinase
}

\author{
C M Schambeck, M Wick, R Bartl, R Lamerz, A Fateh-Moghadam
}

\begin{abstract}
Aims-The labelling index as defined by the percentage of bone marrow plasma cells doubling their DNA in the $\mathbf{S}$ phase is a useful prognostic factor in multiple myeloma. The aim of this study was to examine the specificity and sensitivity of a new flow cytometric method for measuring the labelling index.

Methods-Bone marrow specimens from five patients with monoclonal gammopathy of undetermined significance and 61 patients with multiple myeloma were investigated. The labelling index (LI\%) was determined by means of a microscopic and flow cytometric method using the antibromodeoxyuridine antibody BU-1. Serum thymidine kinase, another index of proliferation, was measured by radioimmunoassay.
\end{abstract}

Results-Good comparability $(r=0.83)$ and nearly equal imprecision $(\mathrm{CV}<20 \%)$ were found with microscopic and flow cytometric methods of LI\% measurement. However, 1000 or more cells had to be counted by microscopy around the cutoff value to avoid an unacceptable imprecision. Plasma cells with increased $S$ phase $(L I \%>1 \%)$ were characterised by their reduced light chain fluorescence intensity ratio between plasma cells and nonspecifically stained cells $(7.9 v v 14.8$, $\mathbf{p}<0.002$ ), that is, by their generally lowered cytoplasmic immunoglobulin content. There was a moderate correlation between thymidine kinase and labelling index $(r=0.56, p<0.001)$. At $100 \%$ specificity, myelomas with proliferating plasma cells were more sensitively detected by the labelling index than by serum thymidine kinase (55\% v 32\% sensitivity).

Conclusions-The labelling index represents a more specific and sensitive proliferation marker than serum thymidine kinase. Flow cytometry does not result in greater precision.

(f Clin Pathol 1995;48:477-481)

Keywords: Monoclonal gammopathy, flow cytometry, microscopy, thymidine kinase.

Prognostic factors help to assess therapeutic requirements. Survival of myeloma patients also varies according to the growth rate of tumour cells. The study of the proliferation kinetics described by the labelling index (LI\%) provides a means of determining tumour growth. The labelling index describes the percentage of plasma cells in the $S$ phase related to all counted plasma cells. A labelling index of more than $1 \%$ has been shown to be associated with poor survival. ${ }^{1-3}$ The usual but time consuming method of determining proliferation is the incorporation of tritiated thymidine in the $S$ phase DNA. Microscopic evaluation of bromodeoxyuridine uptake instead of thymidine in the $S$ phase DNA using immunofluorescence offers a simpler means of proliferation measurement. Commonly used antibromodeoxyuridine antibodies react only with single stranded DNA which requires pretreatment with $\mathrm{HCl}$ for cleavage. ${ }^{4}$ Gonchoroff et $a l^{56}$ introduced the antibromodeoxyuridine antibody BU-1, avoiding denaturation of DNA due to DNase activity. Cell morphology and surface or cytoplasmic markers thus remain intact.

We tested our newly introduced flow cytometric method to determine the $\mathrm{LI} \%$ with the aid of BU-1. This should give higher precision than microscopy because of the larger number of cells assessed. The aim of this study was to evaluate this flow cytometric method in comparison with the established microscopic method and to assess the clinical value of the LI\% compared to serum thymidine kinase, which also reflects proliferation.

\section{Methods}

PATIENTS

Bone marrow specimens from 29 females and 35 males with monoclonal gammopathy (age 29-81 years) and peripheral blood samples from two patients with a plasma cell leukaemia were examined for determination of $\mathrm{LI} \%$.

The diagnosis of multiple myeloma was based on the presence of two of the following criteria: (1) presence of serum and/or urinary M protein; (2) osteolytic lesions on $x$ ray; (3) myelomatous infiltration in the biopsy sections. The diagnosis of smouldering myeloma fulfilled the criteria of myeloma except for the presence of osteolytic lesions. Monoclonal gammopathy of undetermined significance (MGUS) was characterised by a $\mathbf{M}$ protein concentration of less than $2 \mathrm{~g} / \mathrm{dl}$, absence of skeletal lesions and anaemia, urine $M$ protein $<0.5 \mathrm{~g} / 24$ hours, and absence of morphological plasma cell abnormalities. The most important feature of 
BrdU negative

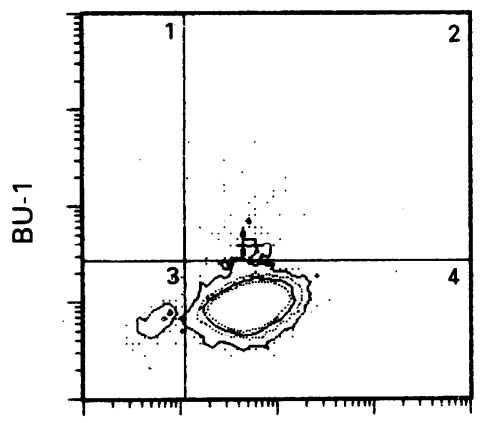

$\lambda C$
BrdU positive

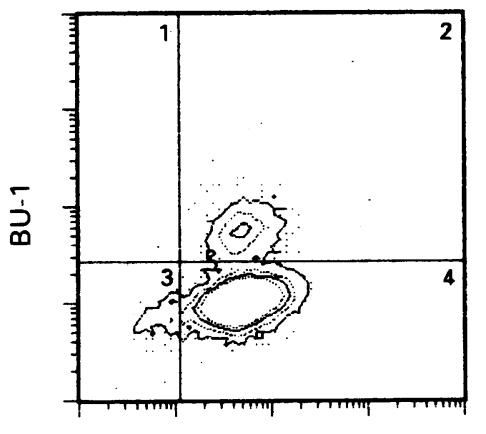

$\lambda \mathrm{C}$
Figure 1 The left contour plot characteristics present bromodeoxyuridine (BrdU) negative cells, the right characteristics present cells incubated with BrdU. Two-colour fluorescence reflects the intensity of staining with BU-1 for anti-mouse antibody and an anti-human light chain antibody. Specifically stained (higher intensities) and autofluorescent nonspecifically stained cells (lower intensities), both distinguished by the crosslines, are shown. This flow cytometric measurement was in a patient with progressive myeloma labelling index (microscopy): $3 \cdot 6 \%$; labelling index (flow cytometry): $3 \cdot 0 \%$ ).

smouldering myeloma and MGUS was the long term stability of the clinical picture and $M$ protein level. A monoclonal immunoglobulin IgG was found in 46 patients, IgA in 11 patients, and $\operatorname{IgG} / \operatorname{IgA}$ and $\operatorname{IgD}$ in one patient each. Five patients suffered from light chain myeloma and two patients from a non-secretory plasmocytoma. Diagnosis of MGUS was established in five cases and of smouldering myeloma in 14 cases. In 15 cases the myeloma was untreated while in 32 cases the disease had been treated at least six weeks ago. Therapy with melphalan and prednisone according to Alexanian $e t a l^{7}$ was used first in all cases with active disease. Blood was drawn at the same time as bone marrow aspiration to measure serum thymidine kinase, the monoclonal immunoglobulin, and other relevant clinical chemical indices. Informed consent was obtained from all patients.

\section{EVALUATION OF DISEASE STATUS}

Patients with smouldering myeloma and MGUS were followed up for at least one year after bone marrow aspiration. Active disease constituted untreated symptomatic myeloma or progressive myeloma during or after treatment. Progression was defined by at least one of the following criteria: an increase of monoclonal immunoglobulin of $>25 \%$, an extension of osteolyses, hypercalcaemia (plasma calcium $>2.75 \mathrm{mmol} / \mathrm{l}$ ), or increased Bence Jones proteinuria (doubling of the protein quantity in $\mathrm{g} /$ 24 hours). Patients characterised by less than a $50 \%$ decrease of monoclonal immunoglobulin after at least six months of therapy, or by lack of a decrease in osteolyses, or by continuation of hypercalcaemia were judged as non-responders.

\section{MEASUREMENT OF THE LI\%}

\section{Flow cytometry}

Mononuclear cells of bone marrow aspirate were obtained by Ficoll-Paque. The cells were incubated for one hour at $37^{\circ} \mathrm{C}$ in RPMI 1640 containing $10 \%$ fetal calf serum, $1 \%$ glutamine,
$0 \cdot 1 \%$ penicillin-streptomycin, $10 \mu \mathrm{M}$ bromodeoxyuridine, and $1 \mu \mathrm{M}$ fluorodeoxyuridine. Cells incubated without bromodeoxyuridine served as controls. The cells were washed and the dispersed pellet was fixed for 30 minutes in $70 \%$ ethanol in order to perforate the membrane. The cells were thoroughly washed twice with cold phosphate buffered saline (PBS). Twenty microlitres of a $1: 4$ dilution of BU-1 (a mouse antibody) were added to the $30 \mu \mathrm{l}$ cell suspension containing 800000 cells, and the mixture was incubated at room temperature for 30 minutes. After washing with cold PBS, $10 \mu \mathrm{l}$ of fluorescein isothiocyanate (FITC) labelled goat anti-human $\kappa$ or $\lambda$ light chain antibody at 1:720 dilution (Southern Biotechnology Associates, SBA) and $10 \mu$ phycoerythrin (PE) labelled goat anti-mouse IgG (SBA), 1:180, were added. The cells were incubated for 30 minutes at room temperature, then washed with cold PBS; $100 \mu \mathrm{l}$ of PBS were added and then 50000 cells were measured with a flow cytometer (FACScan, Becton Dickinson). The raw data were evaluated by Consort 30 software (Becton Dickinson).

The fluorescence profile, that is, the graph showing fluorescence intensity versus the number of counted cells, defined a clear cutoff point: the minimum between the two peaks generated by specifically and non-specifically stained cells was chosen for each fluorescence range. Plasma cells were identified by the higher fluorescence intensity of the FITC labelled cells. The procedure was the same for the control sample data. Four panels were established on the two-colour fluorescence display using these cutoff values which permitted determination of the number of cells counted for each panel (fig 1), and the preliminary LI\% was calculated. The final LI\% was obtained from the difference between the preliminary $\mathrm{LI} \%$ of the bromodeoxyuridine incubated cells and the control sample cells. The signal to noise ratio, that is, the ratio of the preliminary LI\% of the bromodeoxyuridine incubated cells and the control sample cells, had to exceed 2. Otherwise the final LI\% was fixed as 0 . As judged by staining of the cytoplasmic light chains, the ratio of the mean fluorescence intensities of specifically and non-specifically stained cells (RFI) reflects the cytoplasmic immunoglobulin content.

\section{Microscopy}

Fifty thousand cells taken from a suspension of the bromodoexyuridine incubated cells were left for sedimentation on each chosen reaction site of a Bio-rad adhesion slide. The slide was dipped into a $70 \%$ methanol bath for $30 \mathrm{~min}$ utes and then washed with PBS. All the following steps were performed in a humid chamber at $4^{\circ} \mathrm{C}$. First each reaction site was

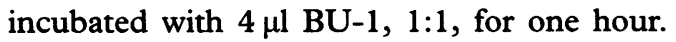
After washing with PBS the reaction sites were incubated with $10 \mu \mathrm{l} \mathrm{PE}$ labelled goat antimouse IgG (SBA), 1:10, and $10 \mu \mathrm{l}$ FITC labelled goat anti-human $\kappa$ or $\lambda$ light chain antibody (SBA), 1:30, for 30 minutes. The slides were washed, mounted, and read in a 
Imprecision of proliferation measurement expressed by the mean coefficient of variation $(C V)$

\begin{tabular}{|c|c|c|c|}
\hline & \multicolumn{3}{|c|}{ Coefficient of variation (\%) } \\
\hline & \multicolumn{2}{|l|}{ Microscopy } & \multirow[b]{2}{*}{$\begin{array}{l}\text { Flow } \\
\text { cytometry }\end{array}$} \\
\hline & $\begin{array}{l}500 \\
\text { plasma cells }\end{array}$ & $\begin{array}{l}>1000 \\
\text { plasma cells }\end{array}$ & \\
\hline $\begin{array}{l}\text { Labelling index } \leqslant 2 \% \\
\text { Labelling index }>2 \%\end{array}$ & $\begin{array}{l}38 \\
23\end{array}$ & $\begin{array}{l}20 \\
13\end{array}$ & $\begin{array}{l}19 \\
17\end{array}$ \\
\hline
\end{tabular}

In each category (labelling index $<2 \%$ or $>2 \%$ ) bone marrow of four patients was examined. At least 500 plasma cells and 1000 plasma cells were microscopically counted six and three times, respectively. Bone marrow of two or three patients was analysed in each described category to determine imprecision of flow cytometric measurement. In one series, because of limitations of cell quantity of the aspirate, repeated measurements were made only a few times.

Zeiss fluorescence microscope. $S$ phase plasma cells were then detected by simultaneous identification of green cytoplasmic light chains forming a ring around the red nucleus of the cell.

\section{BONE MARROW HISTOLOGY}

Procedures are described by Bartl et al. ${ }^{8}$ Less than 20 vol\% plasma cell infiltration of the bone marrow was considered as a low degree of infiltration, whereas more than $20 \mathrm{vol} \%$ was regarded as a high degree of infiltration.

\section{OTHER ASSAYS}

Serum thymidine kinase was measured by means of the "Prolifigen" radioimmunoassay (Sangtec Medicals). The monoclonal immunoglobulin was measured using a nephelometer (Behring). Protein in the urine was determined by the Biuret method. Monoclonality was confirmed by immunoelectrophoresis or immunofixation.

\section{STATISTICAL ANALYSIS}

Differences among groups were analysed by the Wilcoxon Mann-Whitney test. Correlations were determined using the Spearman correlation procedure.

\section{Results \\ METHODOLOGICAL EVALUATION \\ Labelling index}

A comparison was made between the microscopic and the flow cytometric method. Table 1 shows the imprecision data obtained for $\mathrm{LI} \%$. A coefficient of variation (CV) of more than $20 \%$ if 500 plasma cells were counted was found for microscopy, whereas a CV of less than $20 \%$ could be shown for the flow cytometric method. However, precision of the microscopic method could be improved to less than $20 \%$ $\mathrm{CV}$ by counting at least 1000 plasma cells. In order to obtain a CV of less than $20 \%$ the following analysis uses microscopical LI\% values based on at least 1000 cells around the decision limit or 500 cells in cases with more than $2 \%$ proliferating plasma cells. Correlation analysis of both $\mathrm{LI} \%$ methods showed good comparability $(r=0.83, p<0.001$, slope $=1 \cdot 05$, intercept $=+0 \cdot 17, \mathrm{n}=46$ ) (fig 2). By defining the cutoff value of $\mathrm{LI} \%=0 \cdot 8 \%$ for microscopy and (according to the regression line) $\mathrm{LI} \%=$

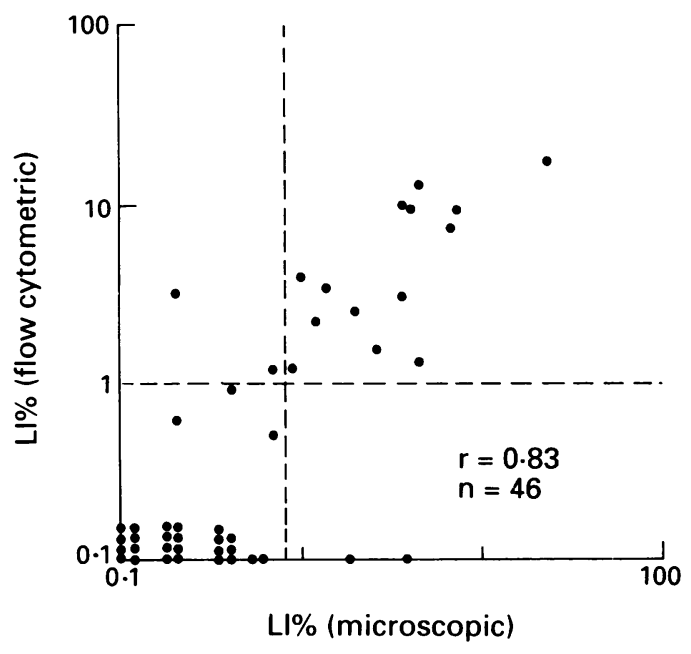

Figure 2 Correlation analysis of labelling index ( $\mathrm{LI} \%$ ) using microscopy and flow cytometry. Note the logarithmic scales; $0 \cdot 1$ was set instead of $0 \cdot 0$. Dashed lines indicate cutoff values.

$1.0 \%$ for flow cytometry, four cases were not identically described by low or high levels of proliferating plasma cells. If more than $1 \cdot 0 \%$ proliferating plasma cells were found by the flow cytometric method the cytoplasmic immunoglobulin content as revealed by the RFI was significantly reduced $(\mathrm{p}=0.002, \mathrm{RFI}=7 \cdot 9$, $\sigma=5 \cdot 1, \mathrm{n}=13 v \mathrm{RFI}=14 \cdot 8, \sigma=8 \cdot 6, \mathrm{n}=29$ ). This was also true for the untreated patients or patients treated at least eight months ago $(n=29, p=0.01)$. Degree of plasma cell infiltration estimated by bone marrow biopsy did not affect cytoplasmic immunoglobulin content expressed as RFI ( $n=35, p=0.09)$.

\section{Thymidine kinase}

Serum samples were measured six times to determine intra-assay and interassay imprecision of thymidine kinase measurements. Imprecision was reflected by an intra-assay $\mathrm{CV}$ of $5 \%$ and an interassay $\mathrm{CV}$ of $6 \%$ for values $>8 \mathrm{U} / 1$ and $<17 \mathrm{U} / 1$.

DEFINING CUTOFF VALUES OF LI\% AND THYMIDINE KINASE

Patients with MGUS and smouldering myeloma had in common a labelling index of less than $0.8 \%$. A thymidine kinase activity of $16 \mathrm{U} / 1$ was set as the $100 \%$ specific cutoff value for MGUS or smouldering myeloma, as was found in the 25 patients with these conditions (data not shown).

\section{DIAGNOSTIC SENSITIVITY}

There was a significant difference in the proliferation kinetics for inactive and active disease $(\mathrm{p}<0.001$ ) (fig 3 ). Defining the cutoff value on the basis of $100 \%$ specificity versus the inactive forms of monoclonal gammopathy (labelling index $<0.8 \%$ ) gave a $57 \%$ sensitivity for active untreated myelomas. Four of seven non-responding patients showed a high $S$ phase fraction in the plasma cells. 


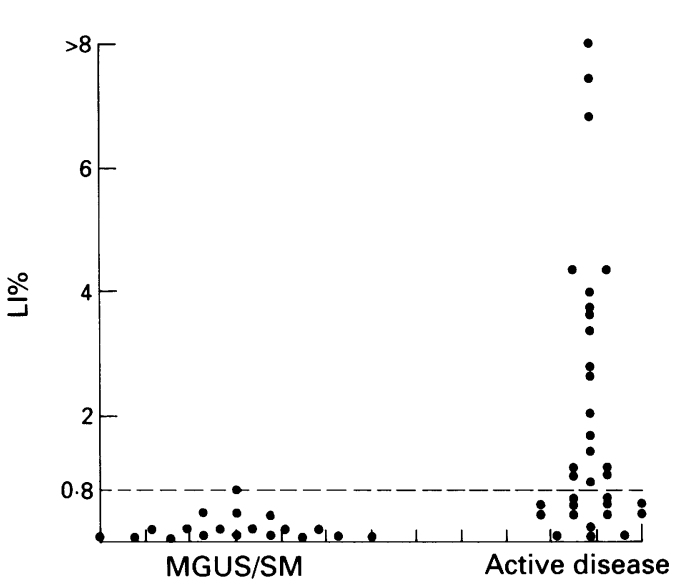

Figure 3 Scatter plot of labelling index (LI\%) values in patients with monoclonal gammopathy of undetermined significance (MGUS), smouldering myeloma (SM), and active myeloma. The data were obtained by microscopic measurement.

Our analyses showed a moderate but significant correlation between thymidine kinase and LI\% $(\mathrm{r}=0.56, \mathrm{p}<0.001, \mathrm{n}=35): 32 \%$ of patients $(7 / 22)$ with active or therapy resistant disease showed raised thymidine kinase values compared to $55 \%(12 / 22)$ with an increased LI\%.

\section{Discussion}

Introduction of the BU-1 antibody in the clinical laboratory provides a rapid method for determining proliferation of myeloma cells, while denaturation can be avoided by DNases. Specificity is crucial if the clinician has to decide to treat. Our results confirmed the excellent discrimination of smouldering and active myelomas shown in other studies. ${ }^{9-11}$ A labelling index of more than $0.8 \%$ indicates an active myeloma with $100 \%$ specificity, which is in accordance with the cutoff values of $0.8 \%$ or $1 \%$ mostly chosen for defining different prognostic groups ${ }^{1-3}$ and differentiating stable and progressive disease..$^{911}$

A negative result despite disease progression can be caused by non-representative puncture location or a great tumour load accompanied by self limiting growth. Some cases with an increased growth fraction following a one week infusion of tritiated thymidine have been reported regardless of a reduced labelling index ${ }^{12}$ and this emphasises the limitations for interpretation of the labelling index. From our experience, values around the lower limit for decision making can become pitfalls if the precision of the method is ignored. It has been proposed that only 500 plasma cells be microscopically counted. ${ }^{51113}$ However, we consider that counting of at least 1000 cells around the decision limit is essential if using microscopy in order to obtain an acceptable degree of imprecision. When this is done the microscopy method and our newly introduced flow cytometric method offer an equal degree of imprecision. A positive identification of the proliferating cell and exclusion of nonspecifically stained cells are possible with microscopy, while flow cytometry enables standardisation and observer independent analysis.

The failure to improve precision by flow cytometry in spite of the greater number of cells counted, and the imperfect correlation of the two methods despite using the same antibodies could be due to two factors. Firstly, ethanol permeabilisation results in temperature dependent shrinkage of cells, intensified autofluorescence, and increased debris so that more non-specific signals are to be expected in flow cytometry. Debris diminishes the signal to noise ratio, especially in cases with low plasma cell infiltration or with low proliferating plasma cell counts. Secondly, B lymphocytes and phagocytosing monocytoid cells could show fluorescence $^{14}$ and in MGUS a high percentage of lymphocyte contamination must be taken into account. However, only correctly identified plasma cells are counted in the microscopy method.

We found a significant inverse correlation between cytoplasmic immunoglobulin content and proliferation of plasma cells. A varying cytoplasmic immunoglobulin content can influence the precision of the flow cytometric method in proliferating myelomas. Total separation of plasma cells from non-specifically stained cells may sometimes be difficult. The very high density of CD 38 on the surface specifically characterises mature plasma cells, but cytoplasmic light chains acting as a plasma cell marker may not be replaced by CD 38 . The prognostically relevant pre-plasma-cells would not be detected. ${ }^{1415}$

The antagonising effect of cytokines inducing mainly proliferation or immunoglobulin production may explain why plasma cells with increased $S$ phase are generally characterised by a lowered immunoglobulin content. ${ }^{16}$ In treated cases therapy not only destroys myeloma cells but possibly diminishes immunoglobulin synthesis of the remaining plasma cells. Infiltration quantity did not influence immunoglobulin content of the plasma cells.

In conclusion, both methods showed good comparability, but methodological and biological effects prevented us from achieving the reduced imprecision which we had hoped for with the flow cytometry method. In certain cases morphological recognition of proliferating plasma cells allows a more reliable determination of the labelling index. Laser scan microscopy could combine the advantages of microscopy and flow cytometry.

The moderate correlation between serum thymidine kinase and the labelling index, as previously shown, ${ }^{1718}$ is not surprising. Thymidine kinase is the key enzyme of the salvage pathway for DNA synthesis, and reutilisation of endogenous thymidine is linked to proliferation. The false nucleotide and thymidine analogue bromodeoxyuridine is inserted by this enzyme, but thymidine kinase and the labelling index are not equivalent from a diagnostic point of view. An important advantage of the proliferation index is the high specificity of the measurement, whereas thymidine kinase is influenced by viral diseases, circadian fluc- 
tuations, and other effects. ${ }^{19}$ The labelling index exclusively identifies the proliferation compartment of myeloma and, unlike thymidine kinase, is independent of tumour extent. At $100 \%$ specificity versus MGUS and smouldering myeloma, the labelling index is the more sensitive proliferation marker.

We thank RA Kyle, P Greipp, and N Gonchoroff from the Mayo Clinic, Rochester (USA) for supplying us with BU-1 antibody. This work was supported by the FriedrichBaur-Stiftung, University of Munich.

1 Durie BGM, Salmon SE, Moon TE. Pretreatment tumor mass, cell kinetics and prognosis in multiple myeloma. mass, cell kinetics and $1980 ; 55: 364-72$.

2 Hofmann V, Salmon SE, Durie BGM. Drug resistance in multiple myeloma associated with in vitro incorporation multiple myeloma associated with in vit
of $3 \mathrm{H}$-thymidine. Blood 1981;58:471-6.

3 Latreille J, Barlogie B, Johnston D, Drewinko B, Alexanian R. Ploidy and proliferative characteristics in monoclonal gammopathies. Blood 1982;59:43-51.

4 Gratzner HG. Monoclonal antibody to 5-bromo- and 5iododeoxyuridine: a new reagent for detection of DNA replication. Science 1982;218:474-5

5 Greipp PR, Witzig TE, Gonchoroff NJ. Immunofluorescent plasma cell labeling indices (LD) using a monoclonal antibody (BU-1). Am ₹ Haematol 1985;20:289-92.

6 Gonchoroff NJ, Greipp PR, Kyle RA, Katzmann JA. A monoclonal antibody reactive with 5-bromo-2-deoxyuridine that does not require DNA denaturation. Cytometry $1985 ; 6.506-12$.

7 Alexanian R, Haut A, Khan AU, Lane M, McKelvey EM, Migliore PH, et al. Treatment for multiple myelomacombination chemotherapy with different melphalan dose regimens. $\mathfrak{F A M A} 1969 ; 208: 1680-5$.

8 Bartl R, Frisch B, Fateh-Moghadam A, Kettner G, Jaeger $\mathrm{K}$, Sommerfeld $\mathrm{W}$. Histologic classification and staging of multiple myeloma. Am 7 Clin Pathol 1987;87:342-55.

9 Boccadoro M, Gavarotti P, Fossati G, Pileri A, Marmont
F, Neretto G, et al. Low plasma cell $3 \mathrm{H}$ thymidine incorporation in monoclonal gammopathy of undetermined significance (MGUS), smouldering myeloma and remission phase myeloma: a reliable indicator of patients mission phase myeloma: a reliable indicator of patients

10 Greipp PR, Kyle RA. Clinical, morphological and cell kinetic differences among multiple myeloma, monoclonal gammopathy of undetermined significance and smoldering multiple myeloma. Blood 1983;62:166-71.

11 Witzig TE, Gonchoroff NJ, Katzmann JA, Therneau TM, Kyle RA, Greipp RP. Peripheral blood B cell labeling indices are a measure of disease activity in patients with monoclonal gammopathies. f Clin Oncol 1988;6:1041-6.

12 Drewinko B, Alexanian R, Boyer H, Barlogie B, Rubinow SI. The growth fraction of human myeloma cells. Blood 1981;57:333-8

13 Girino M, Riccardi A, Luoni R, Ucci G, Cuomo A. Monoclonal antibody $\mathrm{Ki}-67$ as a marker of proliferative activity in monoclonal gammopathies. Acta Haematol 1991;85: in mon.

14 Greipp PR, Witzig TE, Gonchoroff NJ, Habermann TM, Katzmann JA, O'Fallon WM, et al. Immunofluorescence labeling indices in myeloma and related monoclonal gamlabeling indices in myeloma and related mon

15 Omede P, Boccadoro M, Fusaro A, Gallone G, Pileri A. Multiple myeloma: early plasma cell phenotype identifies patients with aggressive biological and clinical characteristics. $\mathrm{Br} \mathcal{F}$ Haematol 1993;85:504-13.

16 Sonneveld P, Schoester M, DeLeeuw K. In vitro Ig-synthesis and proliferative activity in multiple myeloma are stimulated by different growth factors. Br f Haematol 1991; 79:589-94.

17 Brown RD, Joshua DE, Ioannidis RA, Kronenberg $\mathrm{H}$. Serum thymidine kinase as a marker of disease activity in patients with multiple myeloma. Aust $N Z \mathcal{F}$ Med 1989; 19:226-32.

18 Greipp PR, Lust JA, O'Fallon WM, Katzmann JA, Witzig TE, Kyle RA. Plasma cell labeling index and $\beta_{2}$-microglobulin predict survival independent of thymidine kinase and C-reactive protein in multiple myeloma. Blood 1991; 81:3382-7.

19 Hallek M, Wanders L, Strohmeyer S, Emmerich B. Thymidine kinase: a tumor marker with prognostic value for non-Hodgkin's lymphoma and a broad range of potential clinical applications. Ann Hematol 1992;65:1-5. 